\title{
Sensacionalismo e modernidade: como uma relação intrinsecamente ambígua se transformou em estratégia de distinção cultural?'
}

\author{
Wilson Borges (UFF) ${ }^{2}$ \\ Ana Lúcia S. Enne (UFF) $)^{3}$
}

\section{Resumo}

Este artigo apresenta uma breve reflexão sobre a relação entre o contexto histórico de consolidação da modernidade ocidental, em especial o século XIX, e a configuração de uma perspectiva dualista entre domínios que serão apresentados como separados e muitas vezes excludentes: cultura popular $\mathbf{x}$ cultura erudita; imprensa séria $x$ imprensa sensacionalista; razão e sensação, dentre outros. Nosso objetivo é demonstrar que tais dualidades são, em grande medida, resultado de um processo de construção cultural, em que classes privilegiadas - em especial a média e alta burguesia - irão promover, através de diversos recursos, estratégias de distinção, negando, dessa forma, o fluxo e a circularidade cultural.

Palavras-chaves: Sensacionalismo; modernidade; mediações culturais; fluxo cultural; distinção

\begin{abstract}
This article brings an approach to the relationship between the historical consolidation context of occidental modernity, specially in the XIXth century, and the birth of a dual perspective relating areas that are usually given as separated or even excluding: popular culture and erudite culture, serious press $x$ sensationalist press, rationality and feelings, among others. Our goal is to show that much of such divisions result from a cultural construction process in which privileged classes - specially medium and high classes - produce, using different resources, strategies for distinguishing. Thus they refuse the cultural circularity and flow.
\end{abstract}

Keywords: Sensationalism, modernity, cultural mediation, cultural flow, distinguishment 


\section{Introdução}

Este artigo apresenta uma breve reflexão, que nos servirá de base para postulações futuras, ${ }^{4}$ sobre a relação entre o contexto histórico de consolidação da modernidade ocidental, em especial o século XIX, e a configuração de uma perspectiva dualista entre domínios que serão apresentados como separados e muitas vezes excludentes: cultura popular e cultura erudita; imprensa séria e imprensa sensacionalista; razão e sensação, dentre outros. Nosso objetivo é demonstrar que tais dualidades são, em grande medida, resultado de um processo de construção cultural, em que classes privilegiadas - em especial a média e alta burguesia - irão promover, através de diversos recursos, estratégias de distinção cultural e social. Neste sentido, mascarando o caráter ambíguo, mestiço e de fluxo dos domínios acima citados, tais classes irão legitimar determinados atributos culturais como melhores do que outros, marcando com estigmas uma gama de produtos da cultura moderna, dentre os quais a imprensa dita "sensacionalista".

Assim, em última instância, nossa proposta aqui é tentar complexificar a associação entre imprensa sensacionalista e popular. Mais especificamente, como certa construção do lugar do popular confere a este, na modernidade, o estatuto de algo inferior se comparado ao de uma elite que, historicamente, construiu estratégias de distinção no campo da cultura. Nesse sentido, a ilusória distinção entre cultura popular e cultura erudita estaria a camuflar uma distinção fundada no gosto, onde esta última consumiria aquilo que é nobre, sublime, culto, e aquela o mundano, baixo, o vulgar. No entanto, essa distinção, como veremos, tem servido à tentativa de se produzir lugares sociais fixos (se é que isso é possível) numa sociedade altamente estratificada, como é o caso da brasileira, por exemplo. Assim, estará nos interessando neste artigo estabelecer alguns parâmetros que aparecem na configuração das categorias popular e sensacional, marcadas por diversos sentidos pejorativos quando associadas à construção discursiva de um segmento da imprensa.

A nossa problemática tem se desenvolvido no sentido de apontar que 0 antagonismo social, ou a luta de classes como nomeou Marx, está presente não só no campo estrito da política, mas no da cultura, este entendido em seu sentido mais amplo. Assim, estamos concebendo Cultura como arena de 
disputas e conflitos, mas também como espaço de mediação e de hibridização, de produção de sentidos e de significados. Ao pensarmos a Cultura dessa forma, é fundamental que compreendamos que essa busca por produzir sentidos, revela, em si mesma, uma disputa por produzir memória, identidade e projetos. Ou seja, o que estamos buscando apontar é o caráter processual (sempre circular) da dinâmica cultural, sem perder de vista o jogo complexo que envolve tanto resistência quanto negociação. Com isso, partilhamos da proposta de diversos autores, no campo especialmente dos Estudos Culturais e das Mediações, de recusa da dicotomia simplificadora entre cultura popular versus cultura erudita.

\section{Modernidade e experiência: a construção de um novo ethos}

Para avançarmos na discussão em torno da relação entre cultura e sensações, é necessário que façamos mais algumas observações. Estamos tomando como ponto de partida, tomamos o conceito de cultura (XVIII-XIX) como uma invenção da modernidade, inserindo-o no processo histórico das transformações sociais, sobretudo a partir da invenção da eletricidade, das inovações tecnológicas (comunicação e transporte) e dos adventos das metrópoles. Como ponto de chegada, o lugar ocupado pelo sensacionalismo (ou pelas sensações) na construção de um novo ethos associado à modernidade. Ou seja, queremos compreender as especificidades e as transformações pelas quais as sensações (e por extensão, a noção de sensacionalismo) vão passar ao longo do processo que se põe em movimento com a instauração da ordem burguesa.

Assim, no contexto de nossas reflexões, é interessante visualizarmos o processo de expansão do capitalismo industrial, na passagem do século XVIII para o XIX, e o impacto que o mesmo produziu na cena pública. Em O declínio do homem público (1988), Richard Sennett traça um interessante panorama sobre como o capitalismo industrial vai produzir transformações nas personalidades e atitudes do homem do século XIX, em especial àquele submetido às experiências urbanas.

Segundo Sennett, no contexto da modernidade, estaríamos diante de uma cidade que passa a ser o lugar da problemática social, na qual uma 
cultura dinâmica de troca cede lugar a uma cultura das aparências - cultura do consumo, mais ainda, cultura do consumo das aparências - e que, como aponta Sennett, terá a burguesia se constituindo como a classe crítica.

Um dos efeitos que se produz é que "a rotina da vida diária passada fora do quartier estava se tornando uma experiência urbano-burguesa; os sensos de se ser cosmopolita e de se ser membro das classes burguesas passaram, então, a ter certa afinidade" (SENNETT, 1988: 174).

Esse cosmopolitismo, associado às transformações do comércio de mercadorias - sai a relação sujeito-sujeito e entra a eu-objeto, com a emergência da loja de departamentos - reconstrói também a relação entre os sujeitos sociais. O objeto passa a ser fonte de subjetivação e as relações passam a ser permeadas pelo objeto - agora produzido em escala industrial. É a tal transformação que Sennett se refere ao destacar que "a verdadeira mudança de contexto estava naquilo que comercializavam e administravam: um sistema de mercadorias feitas à máquina e produzidas em massa" (ibid.: 176).

Mudança de atitude. Mudança de personalidade. Eis um efeito prático que as novas condições materiais produziram. Conseqüentemente, alteraramse também as relações sociais. É interessante perceber como essa nova personalidade vai se desenvolver: a partir da distinção eu x outros. Melhor dizendo: sinais que significam e distinguem o self em relação aos demais. Ou como destaca Sennett: "uma pessoa conhecia verdadeiramente uma outra entendendo-a em seu nível mais concreto, que consistia em detalhes da roupa, do discurso, do comportamento. Nas roupas e nos discursos da Paris de Balzac, as aparências já não eram mais um distanciamento do eu, mas antes pistas para um sentimento privado. Inversamente, o 'eu' não mais transcendia suas aparências no mundo. Esta era a condição básica da personalidade" (SENNETT, 1988: 194).

O sistema capitalista vai se servir desta distinção, investindo nos símbolos e nos sinais físicos como possibilidade de comércio (e de lucro). Há, como indica o autor, "uma superposição de imaginário em domínios que, no Antigo regime, eram mantidos separados" (SENNETT, 1988: 194).

Sennett aponta que o trabalho da propaganda industrial se fez por um ato de desorientação, dependente de uma superposição de imagens, que por 
sua vez foi dependente tanto de um modo distintivo de produção, quanto de uma crença distintiva sobre a presença universal do caráter humano. Na verdade, antes de representar desorientação, julgamos que a propaganda reorientou as relações numa perspectiva que produziu como efeito: "uma cultura de mobilidade voraz (baseada na distinção), reveladora de uma psique humana totalmente emancipada de obrigações estáveis, deveres, contatos feudais, laços tradicionais. Na cidade, corrupções banais, pequenas crueldades involuntárias, parecendo deslizes insignificantes, tornaram-se absolutos valores morais: não havia mais princípios transcendentes como reis ou deuses para se operarem a essas crueldades. A cidade expunha assim todas as possibilidades da psicologia humana" (ibid:: 196).

Ou seja, o que a propaganda reorienta é a perspectiva da aparência ser um índice do caráter humano. Tal perspectiva nos coloca em contato com Simmel e a noção de transformação da vida mental que a metrópole permite.

Georg Simmel observa que "os problemas mais graves da vida moderna derivam da reivindicação que faz o indivíduo de preservar a autonomia e individualidade de sua existência em face das esmagadoras forças sociais, da herança histórica, da cultura externa e da técnica de vida" (1979: 11). Ou seja, como pode o indivíduo se mover nessa cidade que muda os fundamentos sensoriais da vida psíquica, a cidade moderna? Para o autor, a cidade moderna é uma cidade hiperestimulante. Nessa perspectiva, Simmel parte da oposição rural versus urbano, destacando as condições psicológicas que esta cria: "com cada atravessar de rua, como o ritmo e a multiplicidade da vida econômica, ocupacional e social, a cidade faz um contraste profundo com a vida de cidade pequena e a vida rural no que se refere aos fundamentos sensoriais da vida psíquica. A metrópole extrai do homem, enquanto criatura que procede a discriminações, uma quantidade de consciência diferente da que a vida rural extrai" (ibid.:12).

O autor, porém, não valora uma cidade em relação à outra. Antes, as distingue. Ao opor comunidade e associação, campo e cidade grande, coletivismo e individualismo, Simmel busca destacar as especificidades que cercam cada uma. Tomemos por exemplo a questão da liberdade. Para o sociólogo alemão, a metrópole "confere ao indivíduo uma qualidade e quantidade de liberdade pessoal que não tem qualquer analogia sob outras 
condições" (ibid.:18). Ou seja, a sociedade liberta, enquanto a comunidade aprisiona. A comunidade dá visibilidade, expondo, enquanto a metrópole protege, mantendo o anonimato. É o próprio Simmel quem afirma: "não são apenas o tamanho imediato da área e o número de pessoas que, em função da correlação histórica universal entre o aumento do currículo e a liberdade pessoal interior e exterior, fizeram da metrópole o local da liberdade. É antes transcendendo essa expansão visível que qualquer cidade dada se torna a sede do cosmopolitismo" (ibid.: 20).

Mas, não podemos perder de vista (e o autor não perde) que há diferenças significativas entre a vida na comunidade e a vida na metrópole, sobretudo no que diz respeito à inter-relação. Como pode então o sujeito se adaptar à vida cosmopolita? Como conviver com esse hiperestímulo? A solução seria a construção de uma estrutura intelectual consistente. No entanto, frente ao processo acelerado de massificação, Simmel indica que o homem moderno, em geral, só consegue oferecer como resposta a adoção de uma atitude blasé: experimentar sensações fortes para, em seguida, anulá-las, construindo, assim, uma segurança psíquica através da recusa do sensacionalismo.

Percebemos, então, uma aparente contradição na construção do imaginário ocidental na modernidade do século XIX: existe um esforço em conjurar as sensações, recusadas por seu excesso e desvalorizada frente à contenção erigida pela burguesia como recurso fundamental para a distinção social; ao mesmo tempo, existe, como descreve Ben Singer (2001: 116), a partir das considerações de Simmel, uma "intensificação da estimulação nervosa", com a exploração exacerbada do sensorial. Entendemos que tal contradição, na verdade, deveria ser pensada como uma ambigüidade constitutiva desse processo cultural, como indicaremos a seguir.

\section{Sensações fora de lugar?}

Nós, pelo que dissemos até agora, queremos reter a idéia de que a modernidade é hiperestimulante ${ }^{5}$. Como destaca Singer, "revistas cômicas e jornais sensacionalistas observaram de perto o caos do ambiente moderno com um alarmismo despótico que, em graus variáveis, caracterizou muito do 
discurso do período sobre a vida moderna" (2001: 119). Fazendo referência ao pensamento de Benjamin, ele alude ao fato de "que medo, repulsa e horror eram emoções que a multidão da cidade grande despertava naqueles que a observavam pela primeira vez" (ibid.: 119). O sensacional que aparecia nas publicações da época dava conta das transformações produzidas por uma modernidade que desequilibrava e desestabilizava a época precedente. Singer destaca várias publicações que demonstravam uma "predileção particular por imagens de 'instantâneos' de mortes de pedestres. Essa fixação ressaltava a idéia de uma esfera pública radicalmente alterada, definida pelo acaso, pelo perigo e por impressões chocantes mais do que por qualquer concepção (...) de segurança, continuidade e destino autocontrolado" (ibid.: 126). Cremos que Singer consegue capturar o fluxo do sensacionalismo como processo quando aponta que "os retratos da modernidade urbana na imprensa ilustrada parecem flutuar entre uma nostalgia antimoderna de uma época mais tranqüila, de um lado, e uma fascinação básica pelo horrível, pelo grotesco e pelo extremo, de outro. As imagens da imprensa ilustrada eram, paradoxalmente, uma forma de crítica social e, ao mesmo tempo, uma forma de sensacionalismo comercializado, uma parte do fenômeno do hiperestímulo moderno que as imagens criticavam" (ibid.:. 132-133).

Podemos enfocar também outro tipo de aproximação entre Sennett, Simmel e Singer. O primeiro destaca que os anos de 1840 foram a primeira grande circulação maciça de jornais. Já Singer, que uma das faces dessa circulação amplificada se erigiu a partir de um sensacionalismo grotesco que vendia jornais, se aproximando de Simmel para quem esse aumento representava os reflexos de uma sociedade hiperestimulante. O que não está dito, mas que aparece implicitamente, é que uma das características desses jornais modernos é falar a um público distinto das camadas mais rurais. Isso poderia passar a falsa impressão de que a imprensa do século XIX se dirigia a uma camada social superior (a urbana), contribuindo para forjar níveis de cultura. ${ }^{6} \mathrm{O}$ que estamos querendo dizer é que existiam práticas de leitura prémodernas que vão atravessar a modernidade, concorrendo com as práticas modernas.

Vejamos algumas marcas da presença dessas práticas de leitura prémodernas na modernidade. Carlo Ginzburg destaca a presença da 
circularidade e da oralidade na Europa pré-industrial. Para ele, "uma cultura oral que era patrimônio (...) de um vasto segmento da sociedade do século XVI" e que apresentava uma circularidade "entre a cultura das classes dominantes e a das classes subalterna, existindo (...) um relacionamento circular feito de influências recíprocas, que se movia de cima para baixo como de baixo para cima (exatamente o oposto, portanto, do 'conceito de absoluta autonomia e continuidade da cultura camponesa' que me foi atribuído por certo crítico)" (1997: 12).

A presença de Bakhtin em Ginzburg é fundamental. Se há uma clara ruptura entre o período pré-moderno e o moderno, essa se dá com as propostas de grande parte do campo estético acerca do grotesco, que, para Bakhtin, era elemento constitutivo fundamental na cultura popular medieval e do Renascimento. "A partir da segunda metade do século XIX, o interesse pelo grotesco diminui notavelmente, tanto na literatura como na história literária. Quando se faz alusão a ele, é para relegá-lo às formas do cômico vulgar de baixa categoria, ou para interpretá-lo como uma forma particular de sátira, orientada contra fenômenos individuais, puramente negativos. Dessa maneira, toda a profundidade, todo o universalismo das imagens grotescas desaparecem para sempre" (BAKHTIN, 1993: 39).

No entanto, é preciso perceber que, mesmo relegado a um plano menor, coube ao realismo grotesco papel fundamental na constituição de um discurso atrativo nos jornais do século XIX. Isso nos permite inferir que, mesmo durante o processo de construção da modernidade, a circularidade se fazia presente.

Nos periódicos do século XIX, tal como aponta Singer, algumas formas de expressão do mundo popular vão estar presentes por meio do emprego da linguagem de suas formas e símbolos. Característica que merece destaque é que outro traço marcante do realismo grotesco (o rebaixamento) também estava presente nas construções discursivas modernas, transferindo ao plano material o que era elevado, ideal e abstrato. Entretanto, não é só através da oralidade que a circularidade se fazia presente no contexto da modernidade, pois outras práticas de leitura geravam novas formas de apropriação cultural.

Em Chartier (2004), observa-se que, desde o século XVI, os textos e os livros eram destinados a uma civilidade, ocupando o impresso um papel significativo na circulação dos modelos culturais. Porém, e sem que qualquer 
anacronismo atravesse suas reflexões, o autor destaca que a apropriação dos conteúdos dos escritos se dava por mecanismos outros que não somente a leitura individualizada. Também não estamos menosprezando o fato de que uma parte considerável dos impressos (talvez a maioria) era consumida pelos clérigos, nobres ou letrados. O que buscamos é lançar luz sobre as formas como os leitores populares se apropriavam deste tipo de literatura.

Nesse sentido, o autor oferece um interessante panorama sobre alguns dos mecanismos de apropriação dos impressos. Se tomarmos, por exemplo, a educação no Antigo Regime, podemos perceber, através de Chartier, a aproximação dos mercadores com a nobreza pelo fato de seus filhos estudarem juntos. ${ }^{7}$ Ao abordar os manuseios coletivos do impresso, o historiador francês destaca que uma das principais formas de mediação presente no período pré-moderno é a leitura em voz alta, que acontece em alguns lugares sociais, tais como: oficina ou loja de livros, assembléias religiosas, conferindo o caráter de aprendizagem coletiva desse material. Nas palavras do autor, "reunindo homens e mulheres, letrados e analfabetos, fiéis de profissões e de bairros diferentes, os cultos protestantes, tal como se pode perceber, apesar do segredo que os cerca, nas cidades atingidas pela Reforma, são um dos lugares em que se opera, em comum a aprendizagem do livro" (ibid.:. 101).

Um outro lugar social de apropriação eram as confrarias. Nelas, há a presença de peças que acompanham gestos festivos. Apesar de não fazê-lo claramente, cremos que Chartier se aproxima bastante da reflexão bakhtiniana sobre Rabelais, ao reconhecer o carnaval como um espaço de aculturação pelo escrito. Não que Bakhtin faça qualquer menção à idéia de aculturação em Rabelais. Porém, a partir da perspectiva da teatralização da vida, da inversão, da libertação temporária da verdade dominante e do regime vigente, é possível que esse "segundo mundo", essa ambivalência oferecida pelo rebaixamento, represente de fato um lugar social onde as trocas aumentem. ${ }^{8}$ Mas, nos concentremos um pouco mais em uma das formas de apropriação do impresso, descrito por Chartier: os cartazes. Os cartazes, mas principalmente os avulsos e os pasquins, vão representar um importante instrumento de publicização dos conteúdos impressos, publicização essa que vai desaguar nos jornais modernos. É o próprio Chartier quem argumenta que "Nos séculos XVI e XVII, 
sob formas diversas, que quase sempre autorizam uma dupla leitura, a do texto e a da imagem, a imprensa difundiu amplamente um material tipográfico abundante, destinado a ser fixado, colocado nas paredes das casas e das igrejas, dos quartos e das oficinas. É fora de dúvida, portanto, que desse modo, ela transformou profundamente uma cultura até então privada do contato com o escrito. Semelhante modificação, que tornava familiar o escrito impresso, necessário para a plena compreensão das imagens que eram mostradas, foi certamente decisiva para que uma alfabetização urbana, ao mesmo tempo forte e precoce, criativa, a prazo, fosse levada de um marcado popular para o livro" (ibid.: 113).

Antes de avançarmos, gostaríamos de nos deter com um pouco mais de atenção sobre um dos pontos destacados por Chartier em Leituras e leitores na França do Antigo Regime: o Pasquim. Para nós, a formação de uma estratégia discursiva assentada no sensacionalismo presente na contemporaneidade se alicerça, principalmente, sobre esse ponto. No caso dos pasquins, é interessante destacarmos, primeiramente, a padronização e a regularidade de suas tiragens, sem, é claro, desprezarmos o fato de que as elites urbanas consumiam o seu conteúdo editorial. Apesar de Chartier trabalhar com os primórdios da circulação e consumo em larga escala de textos impressos, a tentação de comparar com a grande imprensa brasileira é grande. Como ressalta o autor: "para além dessas edições camufladas como novidade, é toda a escrita dos pasquins que se abastece num limitado repertório de intrigas e faz uso de um número restrito de fórmulas narrativas. (...) Entre as 517 edições de pasquins (...) seis motivos predominam: os crimes e as execuções capitais (89 edições), as aparições celestes (86), os feitiços e possessões diabólicas (62), os milagres (45), as inundações (37), e os tremores de terra (32)". (ibid.: 115)

É interessante observar que, em larga medida, já encontramos nos pasquins a presença do sensacionalismo. Para nós, não é outra coisa que o autor quer dizer quando afirma que "o pasquim alimenta as imaginações citadinas com narrativas em que o excesso, seja ele o do desregramento moral seja o da desordem dos elementos, e o sobrenatural, miraculoso ou diabólico, rompem com o ordinário do cotidiano" (ibid.: 115).

Ao pensarmos nesse "novo imaginário", somos tentados a abordar a questão do sensacionalismo. Mas, só é valido pensar em sensacionalismo a 
partir da modernidade, ou, melhor dizendo, a partir dos instrumentos modernos de consolidação da sociedade? Evidentemente, como já mencionamos, essas transformações são aceleradas pelo advento da eletricidade e dos transportes. Assim, é no século XIX que se condensam os processos de industrialização, tecnologia e urbanização. Não menos importante é a distinção que a emergência da modernidade conferirá a partir do dualismo razão/emoção, produzindo, por extensão, o dualismo alto mundo/baixo mundo. Esse é o contexto onde as matrizes do melodrama e do folhetim, assim como do faitdivers, se conformaram.

O século XIX é o momento histórico em que se busca apagar os vestígios da circularidade, da polifonia dessas matrizes, que são processuais (embora saibamos que tais vestígios não poderiam ser, de fato, apagados, devido ao caráter circular da cultura). No entanto, ao forjar o dualismo razão/emoção, o projeto iluminista relegou ao segundo o espaço dos excessos, dos sentimentos, das sensações, em uma negação do caráter constitutivo ambíguo do imaginário ocidental.

\section{Algumas conclusões preliminares}

O sensacionalismo, em suas diversas manifestações no universo midiático, nos parece, sem dúvida, um lugar fundamental para percebermos a existência de longos processos de mediações culturais. Neste sentido, apresenta-se como um objeto rico para análise sobre o fluxo narrativo do sensacional e a construção do imaginário na modernidade ocidental, bem como suas reapropriações no decorrer da contemporaneidade. No entanto, é ainda um campo aquém-explorado, ou pela ausência de uma quantidade expressiva de trabalhos (pois os poucos existentes vêm sendo apresentados de forma esparsa), ou pela presença opressiva do preconceito que, muitas vezes, acompanha o processo de formação do gosto de classe, em que estratégias de distinção tendem a relegar o sensacionalismo à vala do mau gosto e, por conseqüência, do mau objeto reflexivo.

No processo de formação da modernidade ocidental, o fluxo ininterrupto de apropriações e reapropriações culturais permitiu o aparecimento de diversas manifestações culturais, geradas a partir de outras e que contribuíram para o 
"fazimento" (como dizia Darcy Ribeiro) de outras mais. Acreditamos que o sensacionalismo da imprensa contemporânea esteja imerso em um imenso leque de matrizes, delas bebendo e também delas se desfazendo, criando novas texturas, conferindo sentidos múltiplos, na perspectiva dialógica e polifônica das práticas discursivas (BAKHTIN,1983).

Assim, acreditamos que as práticas sensacionalistas da imprensa contemporânea são herdeiras (mas não passivas, e sim novas formas de construção e mediação) de algumas matrizes culturais da modernidade ocidental. Em outro trabalho, destacamos as que consideramos mais pertinentes, todas relacionadas ao período que engloba o fim do século XVIII e o decorrer do século XIX: a pornografia, o melodrama, o folhetim, a literatura fantástica e de horror e o romance policial (ENNE, 2007).

Não era nossa intenção, nesse artigo, mapear essas matrizes, mas indicar, através de uma breve explanação, o processo histórico da experiência moderna, que implicará na construção de novas experiências sensíveis, em que o sensacional estará, ambiguamente, muito presente, porém, ao mesmo tempo, sendo continuamente classificado como algo menor e relegado a uma dimensão pejorativa do popular. Como procuramos demonstrar, a circularidade cultural no decorrer da modernidade coloca em xeque tais distinções, revelando imbricamentos onde se buscou construir separações, mediações em vez de níveis estanques de cultura e, principalmente, fluxos e reatualizações e não somente rupturas. 


\section{Referências Bibliográficas}

BARBOSA, Marialva. "Bakhtin, o dialogismo e a circularidade da cultura". Niterói, UFF, 2006, texto mimeo.

BARBOSA, Marialva e ENNE, Ana Lucia. "O jornalismo popular, a construção narrativa e o fluxo do sensacional". Artigo apresentado na LUSOCOM/2006. Santiago de Compostela/Espanha, 2006.

BAKHTIN, Mikhail. A Cultura Popular na Idade Média e no Renascimento. Brasília, Ed. da UNB, 1993.

CHARTIER, Roger. Leituras e leitores na França do Antigo Regime. São Paulo, Ed. UNESP, 2004.

DARNTON, Robert. Os best-sellers proibidos da França pré-revolucionária. São Paulo, Cia. das Letras, 1998.

ENNE, Ana Lucia S. "O Sensacionalismo como processo cultural". Artigo apresentado na COMPÓS/2007. Curitiba, 2007.

GINZBURG, Carlo. O queijo e os vermes. O cotidiano e as idéias de um moleiro perseguido pela Inquisição. São Paulo, Cia. das Letras, 1997.

MARTÍN-BARBERO, Jesús. Dos meios às mediações: comunicação, cultura e hegemonia. Rio de Janeiro, Editora UFRJ, 2001.

MEYER, Marlyse. Folhetim: uma história. São Paulo, Cia. das Letras, 1996.

SCHWARZ, Roberto. Ao vencedor as batatas: forma literária e processo social nos inícios do romance brasileiro. São Paulo, Duas cidades, Ed. 34, 2000.

SENNETT, Richard. O declínio do homem público: as tiranias da intimidade. São Paulo, Cia. das Letras, 1988.

SIMMEL, Georg. "A metrópole e a vida mental”. IN: VELHO, Otávio Gilberto. O fenômeno urbano. Rio de Janeiro, Zahar, 1979.

SINGER, Ben. "Modernidade, hiperestímulo e o inicio do sensacionalismo popular". IN: CHERNEY, Leo; SCHWARTZ, Roberto (org.). O cinema e a invenção da vida moderna. São Paulo, Cosac \& Naify, 2001.

\footnotetext{
${ }^{1}$ Versão ampliada de artigo apresentado no XXX Intercom (NP 02 - Jornalismo), realizado em Santos/SP no mês de setembro de 2007.

${ }^{2}$ Doutorando em Comunicação pela Universidade Federal Fluminense (UFF).

${ }^{3}$ Jornalista e Doutora em Antropologia pelo PPGAS/Museu Nacional/UFRJ. Professora do Departamento de Estudos Culturais e Mídia e do Programa de Pós-Graduação em Comunicação, ambos da Universidade Federal Fluminense (UFF). Coordenadora do Laboratório de Mídia e Identidade/LAMI (www.uff.br/lami).
} 
${ }^{4}$ Em nossos atuais projetos de pesquisa, as reflexões sobre as práticas sensacionalistas na imprensa contemporânea ocupam papel central. Neste artigo, estamos somente apresentando algumas reflexões preliminares, que não têm pretensão nem de esgotar o tema nem de dar conta da questão do sensacionalismo hoje, o que temos feito em outros trabalhos (BARBOSA e ENNE, 2006).

${ }^{5}$ Singer destaca que a expressão foi cunhada por Michel M. Davis em The Exploltation of Pleasure. Nova York, Russel Sage Foundation, 1911, pp. 33-36.

${ }^{6}$ Este é um ponto importante. Se por um lado existiam outras práticas de leitura ao longo do século XIX, não é menos verdade que a produção discursiva desses jornais se destinava a um público diferente (alfabetizado, urbano). Isso também revela que o sensacionalismo era consumido sem distinção por vários segmentos da sociedade.

${ }^{7}$ Situação análoga é a de Menocchio em O queijo e os vermes, onde Ginzburg mostra como o moleiro se apropriava dos conteúdos discursivos que circulavam no Antigo Regime.

${ }^{8}$ Não percamos de vista que Rabelais, assim como outras referências importantes, como Maquiavel, faziam parte de um lista de leituras que circulavam no período pré-moderno. 